\title{
Scanning Electron Microscopy Analysis and Energy Dispersion X-ray Microanalysis to Evaluate the Effects of Decontamination Chemicals and Heat Sterilization on Implant Surgical Drills: Zirconia vs. Steel
}

\author{
Antonio Scarano ${ }^{1,2,3, *}$, , Sammy Noumbissi ${ }^{2,4} \oplus^{\circ}$, Saurabh Gupta ${ }^{2,5}$, Francesco Inchingolo ${ }^{6}$, \\ Pierbiagio Stilla ${ }^{1}$ and Felice Lorusso ${ }^{7}$ (i) \\ 1 Department of Medical, Oral and Biotechnological Sciences and CeSI-Me, University of Chieti-Pescara, \\ 3166100 Chieti, Italy \\ 2 Zirconia Implant Research Group (Z.I.R.G.), International Academy of Ceramic Implantology, Silver Spring, \\ MD 20901, USA \\ 3 Department of Oral Implantology, Dental Research Division, College Ingà, UNINGÁ, Cachoeiro de \\ Itapemirim 29312, Brazil \\ 4 International Academy of Ceramic Implantology, Zirconia Implant Research Group (Z.I.R.G.), University of \\ Chieti-Pescara, 3166100 Chieti, Italy \\ 5 Private Practice Dentistry, Bangalore 560001, India \\ 6 Department of Interdisciplinary Medicine, University of Bari “Aldo Moro", 70121 Bari, Italy \\ 7 Department of Medical, Oral and Biotechnological Sciences, University of Chieti-Pescara, Via dei Vestini, \\ 3166100 Chieti, Italy \\ * Correspondence: ascarano@unich.it
}

Received: 3 June 2019; Accepted: 10 July 2019; Published: 16 July 2019

Featured Application: The control of the effect of drills wear and corrosion related to clinical use represents a critical factor in implantology, because it is strictly related to the bone cutting precision and heat generation during site preparation.

\begin{abstract}
Background: Drills are an indispensable tool for dental implant surgery. Today, there are ceramic zirconium dioxide and metal alloy drills available. Osteotomy drills are critical instruments since they come in contact with blood and saliva. Furthermore, they are reusable and should be cleaned and sterilized between uses. Depending on the material, sterilizing agents and protocols can alter the surface and sharpness of implant drills. The hypothesis is that cleaning and sterilization procedures can affect the surface structure of the drills and consequently reduce their cutting efficiency. Methods: Eighteen zirconia ceramic drills and eighteen metal alloy drills were evaluated. Within the scope of this study, the drills were not used to prepare implant sites. They were immersed for $10 \mathrm{~min}$ in human blood taken from volunteer subjects and then separately exposed to 50 cycles of cleansing with $6 \%$ hydrogen peroxide, cold sterilization with glutaraldehyde $2 \%$, and autoclave heat sterilization. Scanning Electron Microscopy (SEM) and energy dispersion X-ray (EDX) microanalysis were conducted before and after each cycle and was used to evaluate the drill surfaces for alterations. Results: After exposure to the cleansing agents used in this study, alterations were seen in the steel drills compared to zirconia. Conclusions: The chemical sterilization products used in this study cause corrosion of the metal drills and reduce their sharpness. It was observed that the cycles of steam sterilization did not affect any of the drills. Zirconia drill surfaces remained stable.
\end{abstract}

Keywords: implant drills; zirconium dioxide; sterilization; disinfection; cleaning; corrosion; implant failure 


\section{Introduction}

Drill wear is a phenomenon determined by the detachment of particles during the preparation of implant sites that can interfere with the process of bone healing. Considering that all materials are subject to wear and chemical attack by disinfectants, it would be desirable to have a biocompatible drill that is not susceptible to attack by the disinfectants used in clinical practice. The healing of peri-implant bone is a complex phenomenon that involves the proliferation and differentiation of pre-osteoblasts into osteoblasts. Periosteal and endosteal activity also contributes to the production of the osteoid matrix, which is followed by mineralization and organization of the bone-implant interface [1]. The success of implant surgery depends on the bone and soft tissue healing after the process of implant site preparation [2]. One of the key factors in implant success is to keep the osteotomy process as atraumatic as possible for fast, optimal recovery and healing. One of the most important factors in minimizing trauma during osteotomy is to control heat generation with irrigation, but also by utilizing drills that will cut through bone in an efficient and minimally invasive manner [3,4]. Even after a single use, drills will show signs of wear and start to lose their sharpness and cutting efficiency $[5,6]$. A slightly damaged or dulled drill will not only lose its cutting efficiency, but also overheat bone, leading to bone necrosis, poor healing, and an ill-defined osteotomy with a poor initial implant stability $[7,8]$. Among the materials used for the manufacturing of implant drills is steel, whose structural integrity can be affected by disinfectants and cleaning agents. When coming into contact with chemical disinfectants, an oxidation process takes place on the drill, giving rise to corrosion products and the release of metal particles and ions to the peri-implant tissues, which can cause inflammation, increased osteoclastic activity, and subsequent implant failure $[9,10]$.

The phenomenon and mechanism by which the reuse of an implant drill can be a source of metal particles or ions in implant bed preparation have not been evaluated in the literature. Metal particles and ions are known to induce osteolysis, so it is important to avoid potential sources of metal ions and particles for the long-term survival of dental implants. The reuse of drills, repeated cleansing, and sterilization causes them to lose their sharpness and trigger the corrosion process. As a result, there is a loss of cutting efficiency, thus making it possible to leave metal particles and ions in the bone. Furthermore, the loss of cutting efficiency increases the friction between the bone and drills and elevates the osteotomy temperature, leading to bone cell death and implant failure. An alternative drill material to steel is zirconium dioxide, also known as zirconia, which is a ceramic and belongs to the category of materials called inert metal oxides. They are also used as dental implant materials [11]. Zirconia is bio-inert, and has excellent corrosion resistance, superior biocompatibility, high wear resistance, and high fracture resistance values $[12,13]$. Repeated disinfection and sterilization cycles can lead to undesirable changes in the physical properties of the instruments, such as a loss of structure, sharpness, and corrosion [5]. The purpose of this study is to analyze the effects of chemical disinfection and autoclave sterilization on zirconium oxide ceramic drills vs. steel drills by scanning electron microscopy and energy dispersion X-ray microanalysis. The null hypothesis of this study is that there will be no difference in surface alterations between zirconia and steel drills as a result of disinfection and sterilization procedures.

\section{Materials and Methods}

In this study, a total of 18 drills of zirconia (Dental Tech, Misinto, Milan) and 18 steel drills were used (Dental Tech, Misinto, Milan) (Figure 1). 


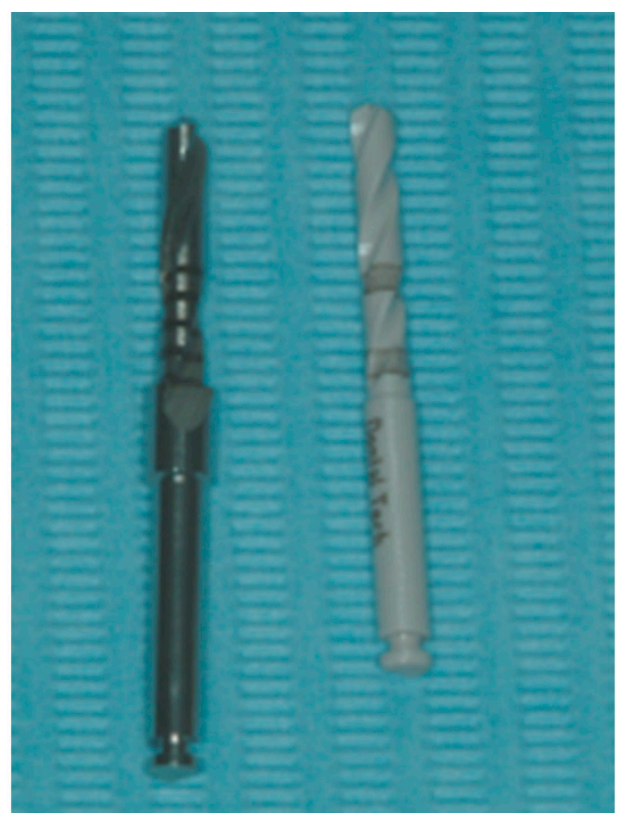

Figure 1. Macroscopic aspect of the steel drill (left) and zirconia drill (right) used in the present study.

Only $2 \mathrm{~mm}$ diameter helical conical drills were evaluated in order to analyze their response to disinfecting and cleansing agents, as well as autoclave sterilization. The steel drills presented the following chemical composition: $0.2 \%$ sulfur, $0.2 \%$ carbon, $0.6 \%$ silicon, $0.8 \%$ nickel, $1.2 \%$ molybdenum, $1.6 \%$ manganese, $16 \%$ chromium, $22 \%$ carbon, and balancing iron. The chemical composition shows the typical characteristics of a stainless-steel alloy. The drills studied were all externally irrigated and had three black laser markings with the function of guiding the surgeon in controlling the depth during osteotomy. In this investigation, chemical agents such as glutaraldehyde $2 \%$ (Dimexid, Amedics Ferrara, Italy) and hydrogen peroxide 6\% (Sanibios, Noda, Balerna- Switzerland), were taken into consideration, and the effect of sterilization cycles was also observed. The drills were not subjected to the preparation of implant sites, but were immersed for 10 minutes in human blood taken from voluntary subjects and then underwent cycles of immersion in disinfectants without being subjected to autoclaving (approved by Inter Institutional Ethics Committee of UNINGÁ, No. 72105917.5.0000.5220). Before immersion, decontamination, or sterilization, the drills were rinsed in running water and scrubbed with a toothbrush made of nylon bristles in order to remove gross foreign material (e.g., organic material, clot). A total of 18 steel drills and 18 zirconia drills were used and allotted to 6 groups of 6 drills, with 6 in steel and 6 in zirconia for each group. Then, implant drills were assessed before and after the disinfection by Scanning Electron Microscopy (SEM). A disc of carborundum was used to separate the blades from the grips of the drills to be observed by SEM. Ten flat areas of $200 \mu \mathrm{m}$ to $150 \mu \mathrm{m}$ in diameter were evaluated for each drill and an image in JPEG format was created (Figure 2). 


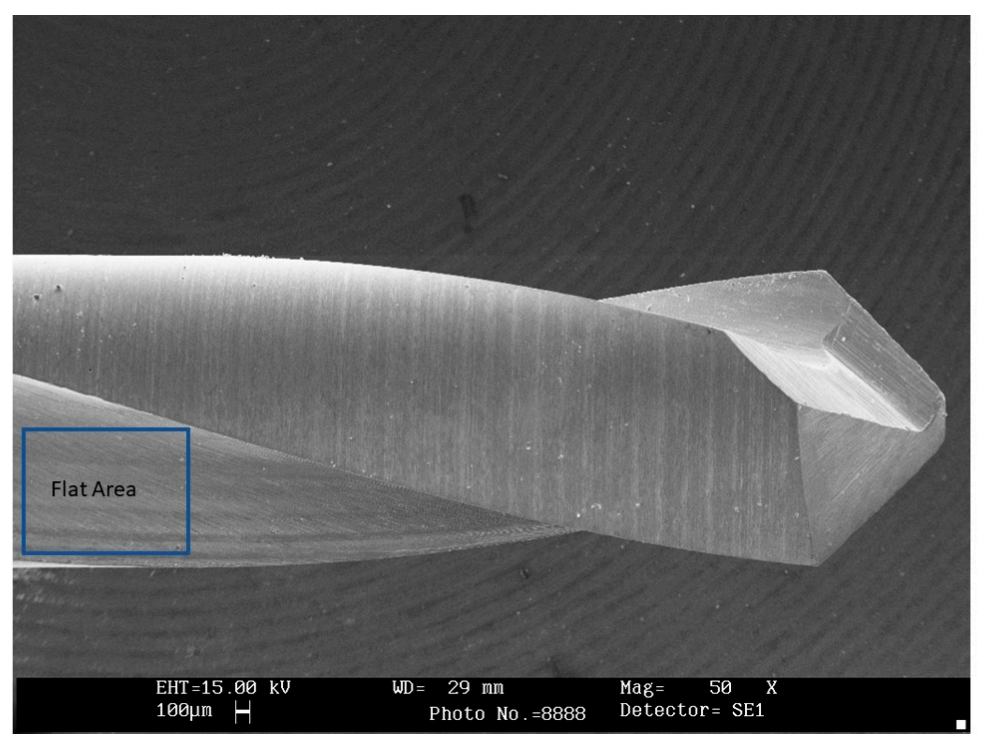

Figure 2. The flat area evaluated for each drill.

The drills were divided into the following groups:

Group 1: New non-sterilized Steel drill; Steel drills subjected to 50 cycles of 20 min sterilization immersion in glutaraldehyde;

Group 2: Steel drills subjected to 50 immersion cycles of 20 min immersion cleansing in hydrogen peroxide;

Group 3: Steel drills subjected to 50 cycles of heat sterilization in an autoclave at $134^{\circ} \mathrm{C}$ for $35 \mathrm{~min}$ at a pressure of $1.1 \mathrm{bar}$; New non-sterilized Zirconia drills;

Group 4: Zirconia drills subjected to 50 cycles of $20 \mathrm{~min}$ immersion sterilization in glutaraldehyde;

Group 5: Zirconia drills subjected to 50 immersion cycles of $20 \mathrm{~min}$ for cleansing in hydrogen peroxide;

Group 6: Zirconia drills subjected to 50 cycles of heat sterilization in an autoclave at $134^{\circ} \mathrm{C}$ for $35 \mathrm{~min}$ at a pressure of 1.1 bar (A-17 PLUS, ANTHOS, Imola, Italy).

All the solutions were poured into a plastic container in order to avoid interference between the liquid and metal. In accordance with the Italian legislation DMS of 28/9/90, the drills were immersed for $20 \mathrm{~min}$ in a liquid chemical sterilant. After 50 cycles of decontamination and cold sterilization immersion, the drills were rinsed in running water and then in demineralized water. They were then observed by a transmission electron microscope. The method of analysis followed the methodology proposed by Scarano et al. [5].

Previously calibrated examiners compared the micrographs before and after 50 cycles of disinfection and sterilization, respectively, with those obtained for the control group and assessed the percentage of surface covered by damage.

\subsection{SEM Observations}

In order to evaluate changes in the surface topography, we used a scanning electron microscope (SEM, JSM-6480LV; Jeol, Tokyo, Japan), with a solid-state backscattered detector operated at a $20 \mathrm{kV}$ accelerating voltage. Each drill was attached to an aluminum stub with sticky conductive carbon tape. Images were taken in both secondary and backscattered electrons. The drills were mounted on aluminum stubs and gold-coated in Emitech K550 (Emitech Ltd., Ashford, UK). Pictures were recorded for each specimen to characterize the surface and presence of corrosion area. The pictures were processed with ImageJ (ImageJ, U.S. National Institute of Health, Bethesda, MD, USA). 


\subsection{Energy Dispersive X-ray Spectroscopy (EDX)}

To detect possible drill alterations, the drills were examined before and after sterilization with a scanning electron microscope/energy dispersion X-ray microanalysis (SEM/EDX) using scanning electron microscopy (SEM, JSM-6480LV; Jeol, Tokyo, Japan) with the EDS QUANTAX-200 probe (Bruker Nano GmbH, Berlin, Germany).

\subsection{Statistical Evaluation}

Free software available on the site http://clincalc.com/stats/samplesize.aspx, was used to determine the number of drills needed to achieve statistical significance for quantitative analyses of drill surface damage. A calculation model was adopted for dichotomous variables (yes/no effect) by applying the effect incidence designed to caution the reasons, with values of $10 \%$ for zirconia drill and $95 \%$ for steel drill, and the alpha was set at 0.05 and power at $70 \%$. The optimal number of specimens for analysis was six drills per group.

A normal data distribution was evaluated by the Shapiro-Wilk test and the differences between the groups were analyzed by one-way analysis of variance (ANOVA) followed by a Tukey post-hoc test. A $p$-value $<0.05$ was considered statistically significant. Data processing and statistical analysis were performed by Excel origin and SPSS software (SPS, Bologna, Italy).

\section{Results}

Scanning Electron Microscopy Analysis and Energy Dispersion X-ray Microanalysis.

\subsection{Steel Drills}

\section{New Non-Sterilized Drill}

The spectroscopic analysis showed that the flat area of implant drills was composed of stainless-steel alloys with a high content of iron, nickel, and chromium (Figure 3).

Group 1

After 50 cycles of decontamination, the drills immersed in the glutaraldehyde showed traces of corrosion with deposits on the bottom of the container and traces of a rust color. The drills appeared to be macroscopically damaged and the laser depth markings were less distinctive, but still identifiable. The areas of corrosion were mostly present especially near the laser markings (Table 1). In total, $21 \pm 3 \%$ of the drill surface in this group was covered by damage (Figure 4 ). None of the drills had surface damage over $30 \%$ of the total surface. The spectroscopic analysis of the drill surface showed a reduction in iron, nickel, and chromium and a comparable increase in oxygen (Figure 5).

\section{Group 2}

The drills immersed in hydrogen peroxide appeared to be macroscopically damaged, but the damaged surface areas were smaller and the laser depth marks remained clearly visible. A total of $12 \pm 1 \%$ of the drill surface in the hydrogen peroxide group was covered by damage. No drill in this group had damage above $20 \%$ of the surface (Figure 6). Additionally, in this group, the spectroscopic analysis of the drill surface showed a decrease in iron levels and a comparable increase in oxygen.

\section{Group 3}

The steel drills that were subjected to 50 cycles of heat sterilization by steam neither caused areas of corrosion nor altered the depth notches (Table 1) (Figure 7). The spectroscopic analysis of the drill surface showed a smaller increase in oxygen and a decrease in the levels of iron, nickel, and chromium (Figure 8). 


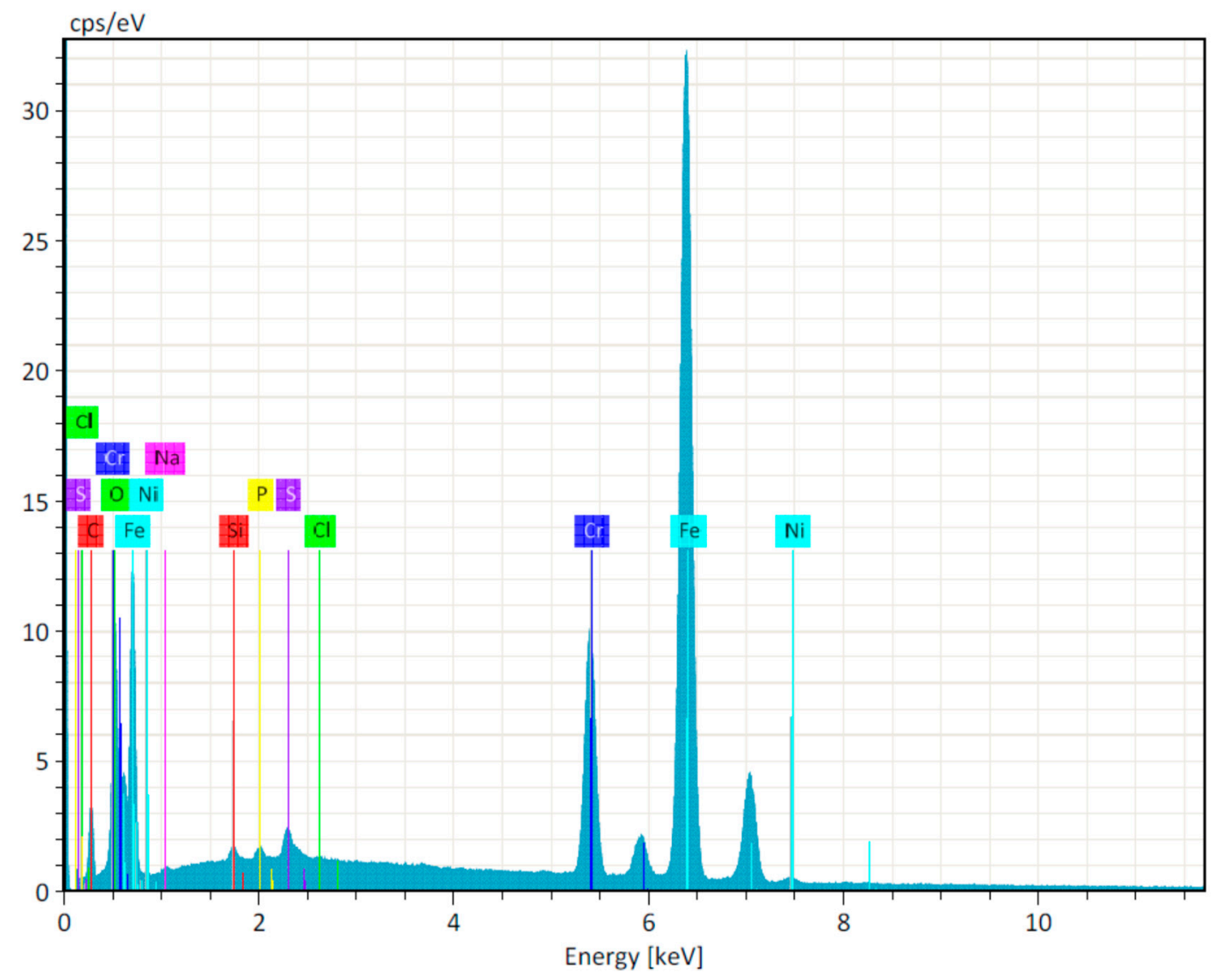

Figure 3. Spectra showing elemental peaks of the new drill surface.

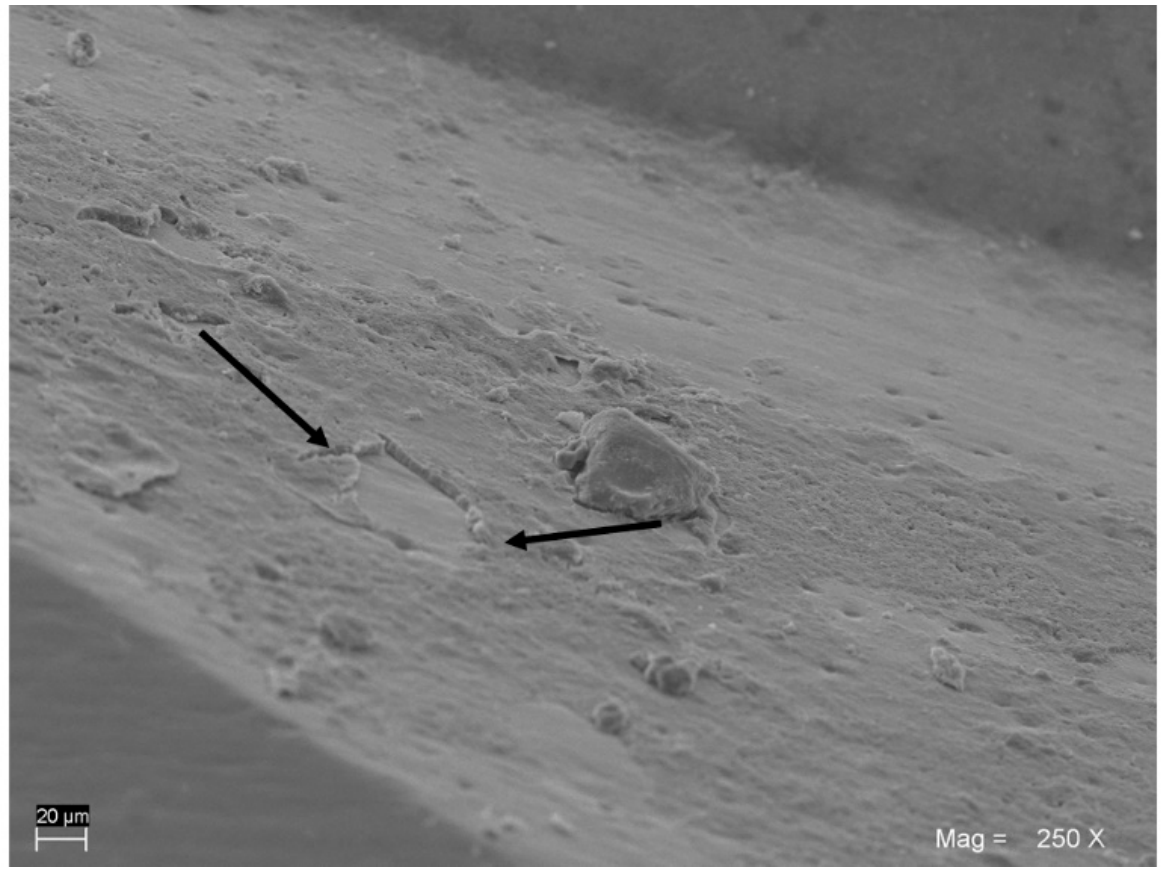

Figure 4. Group 1. Aspects of the steel drill after 50 disinfection cycles with glutaraldehyde, where zones of structural alteration can be observed. 


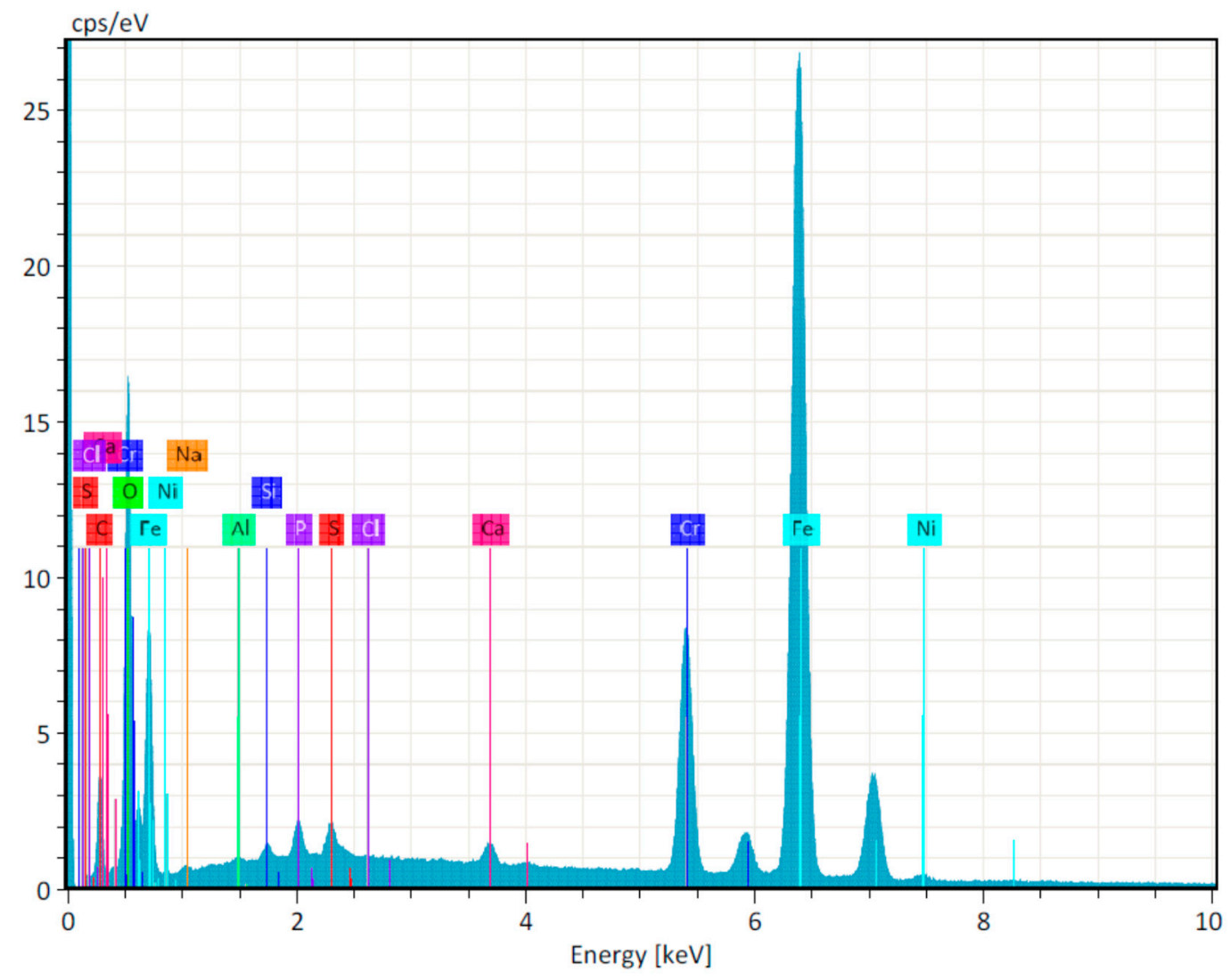

Figure 5. Group 1. The spectroscopic analysis of the drill surface after 50 disinfection cycles with glutaraldehyde showed a decrease in oxygen, iron, nickel, and chromium.

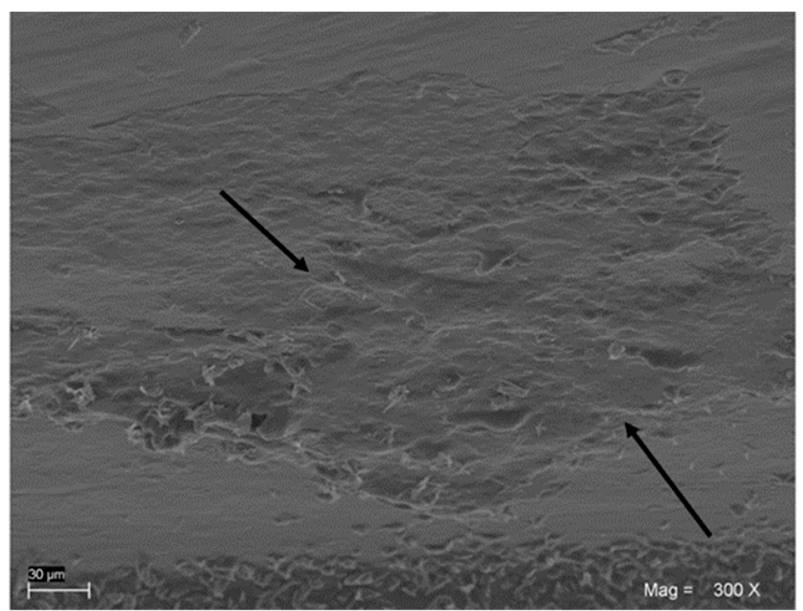

Figure 6. Group 2. After 50 disinfection cycles with hydrogen peroxide, zones of damage by the corrosive process were observed (arrows). 


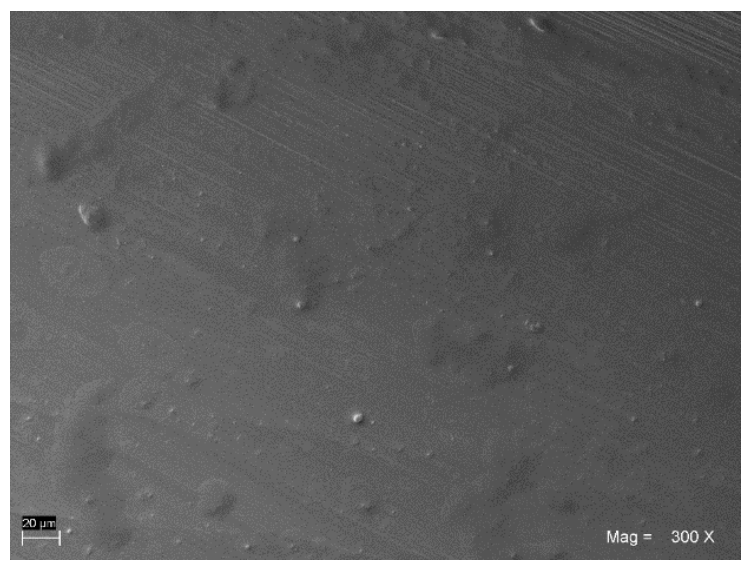

Figure 7. Group 3. After 50 steam autoclave cycles, no areas of corrosion were observed.

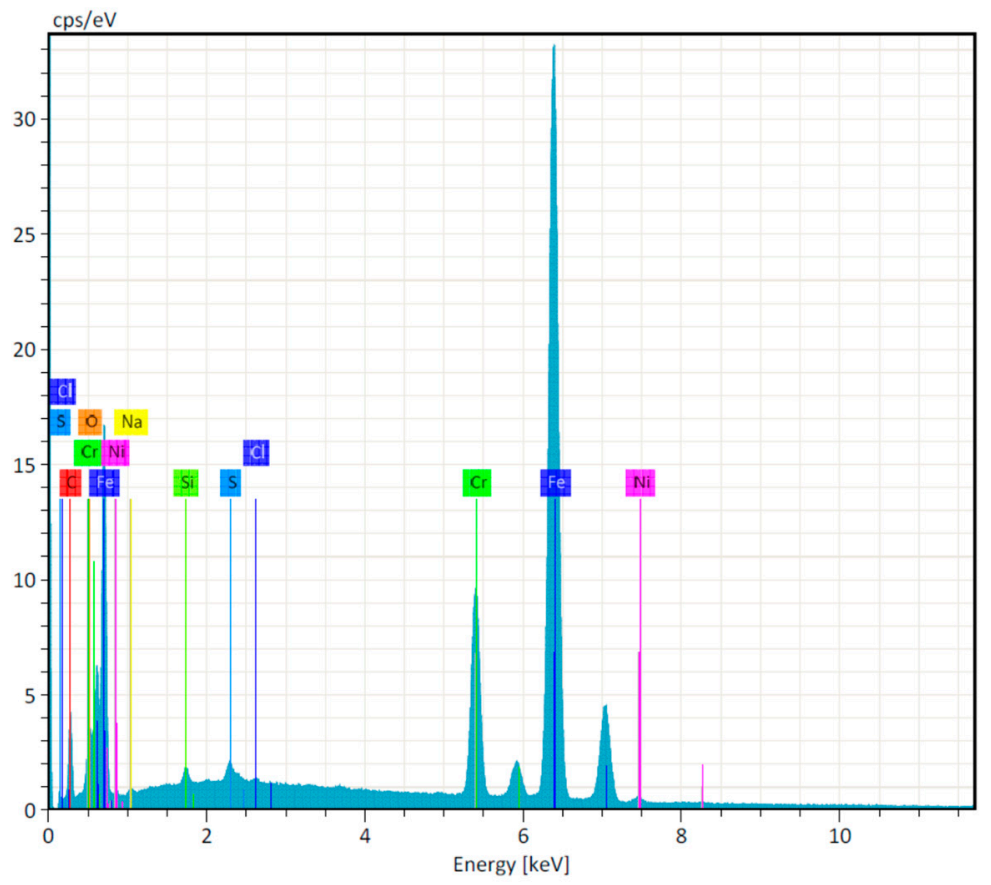

Figure 8. Group 3. The spectroscopic analysis of the drill surface after 50 steam autoclave cycles, where no changes in iron, nickel, and chromium levels and a smaller increase in oxygen where observed.

\subsection{Zirconia Drills}

\section{New Non-Sterilized Drill}

The spectroscopic analysis of the new unsterilized zirconia drill surface showed that the flat areas of implant drills were mainly composed of zirconia and carbon, oxygen, and aluminum (Figure 9).

\section{Group 4}

The zirconia ceramic drills observed after 50 cycles of immersion in the glutaraldehyde had the same appearance as the new non-sterilized drills and did not have residues of organic material (Figure 10). The spectroscopic analysis of the drill surface showed no change in the surface composition. 


\section{Group 5}

The zirconia ceramic drills observed after 50 cycles of immersion in the hydrogen peroxide had the same appearance as the new non-sterilized drills and did not have residues of organic material (Figure 11). The spectroscopic analysis of the drill surface showed no change in the surface composition.

\section{Group 6}

No damage was detected after 50 cycles of heat sterilization in the autoclave, and there was no corrosion or alteration of the laser markings (Figure 12). No differences were observed between the different disinfection liquid immersions (glutaraldehyde and hydrogen peroxide). The black notches that showed the depth and the numbers printed on the drill shanks were intact and showed no signs of damage.

The spectroscopic analysis of the drill surface showed no change in the surface composition.

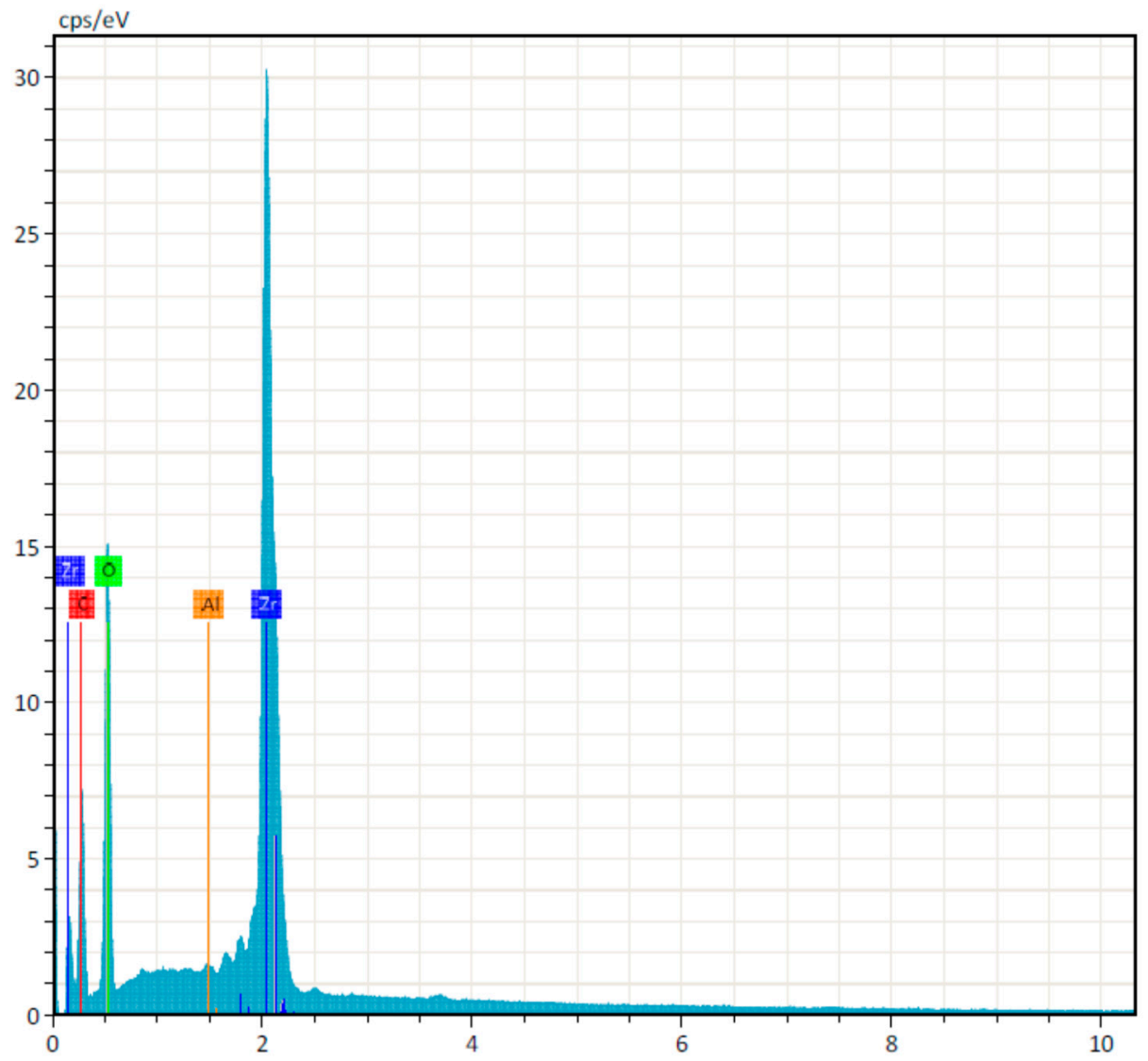

Figure 9. The spectroscopic analysis of the new zirconia drill surface showed that the flat area of implant drills was mainly composed of zirconia. 


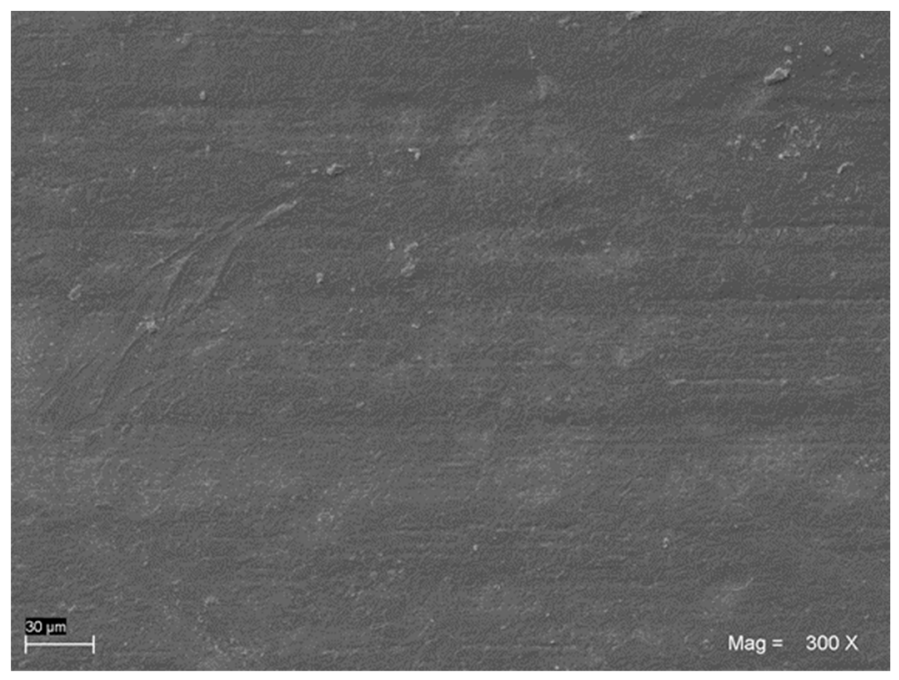

Figure 10. Group 4. The zirconia drill viewed under a scanning electron microscope after 50 disinfection cycles with glutaraldehyde. Sharp margins are free from defects.

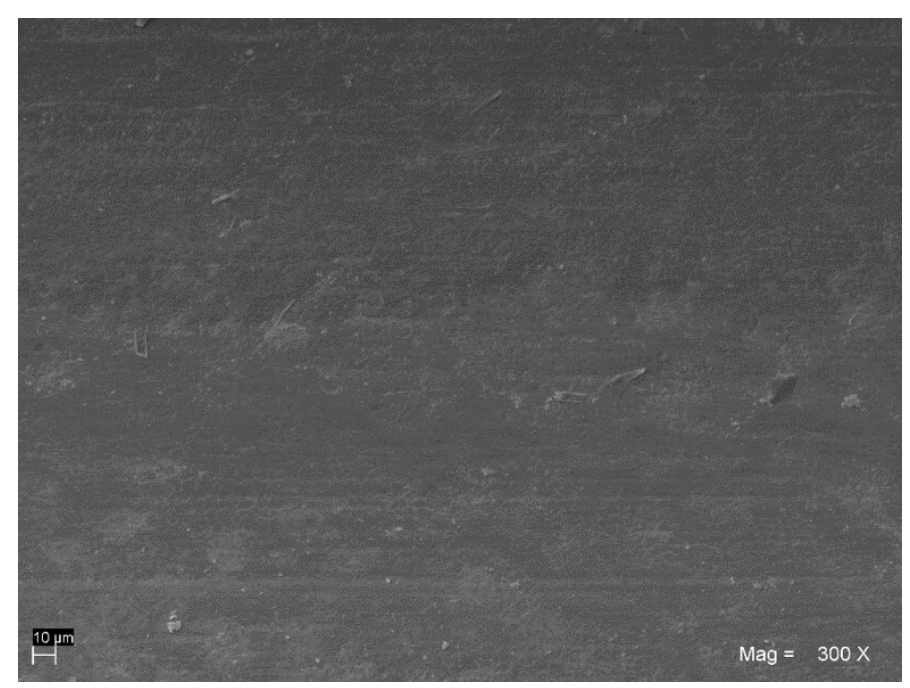

Figure 11. Group 5. The zirconia drill after 50 disinfection cycles with hydrogen peroxide, where no damage was observed on the cutting edges or deposits of other substances. 


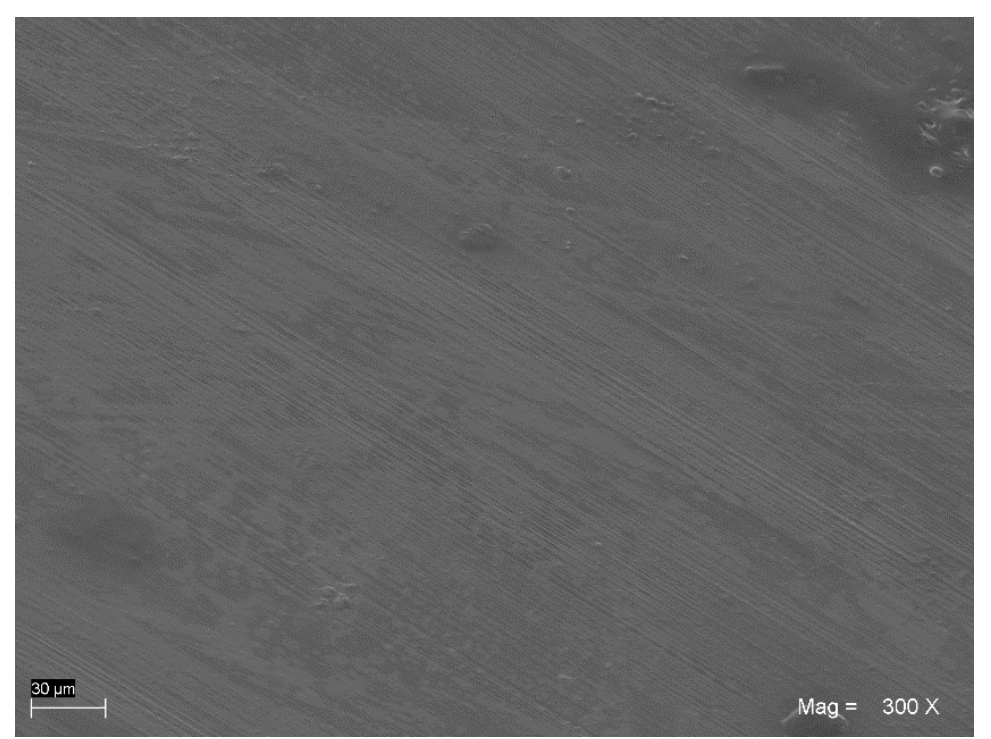

Figure 12. Group 6. After 50 steam autoclave cycles, no areas of corrosion were observed.

Table 1. Summary of the drills surface area damaged by the testing processes. The disinfection processes generated significant surface corrosion compared to the zirconia drills $(p<0.01)$. The autoclave sterilization did not cause any alteration to the different drill surfaces.

\begin{tabular}{|c|c|c|c|c|c|c|}
\hline & \multicolumn{3}{|c|}{ STEEL DRILLS } & \multicolumn{3}{|c|}{ ZIRCONIA DRILLS } \\
\hline & $\begin{array}{l}\text { Group I } \\
\text { (6 drills) }\end{array}$ & $\begin{array}{l}\text { Group II } \\
\text { (6 drills) }\end{array}$ & $\begin{array}{l}\text { Group III } \\
\text { (6 drills) }\end{array}$ & $\begin{array}{l}\text { Group IV } \\
\text { (6 drills) }\end{array}$ & $\begin{array}{l}\text { Group V } \\
\text { (6 drills) }\end{array}$ & $\begin{array}{l}\text { Group VI } \\
\text { (6 drills) }\end{array}$ \\
\hline Mean & $21 \% * *$ & $12 \% * *$ & No Damage ** & No Damage ${ }^{* *}$ & No Damage ** & No Damage ${ }^{* *}$ \\
\hline $\mathrm{SD}$ & $\pm 3 \%$ & $\pm 2 \%$ & - & - & - & - \\
\hline
\end{tabular}

\subsection{Statistical Analysis}

The SEM results showed the drill surface covered by damage and corrosion percentages for the steel drill. A statistically significant difference was found in the percentage of drill surface covered by damage and corrosion on the zirconia drill compared to the steel implant drills $(p=0.000034)$ (Figure 13).

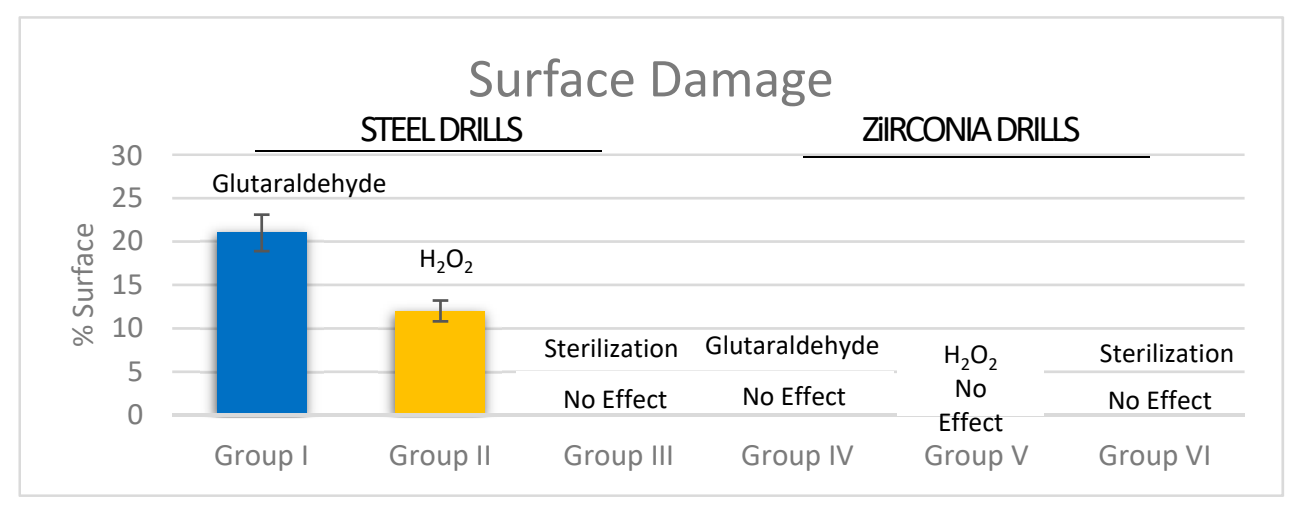

Figure 13. Differences in surface alteration occurred in the different study groups. 


\section{Discussion}

In clinical practice, it is important to avoid cross-infection and it is for this reason that the drills should be treated with disinfectant chemicals, thoroughly rinsed, and submitted to autoclave heat sterilization.

In this study, we used two different disinfection chemicals, namely glutaraldehyde and hydrogen peroxide, which both provide high-level disinfection. The outcomes of the present research showed that zirconia drills are more resistant to the corrosive action of disinfecting chemicals. In fact, a greater difference was found in the percentages of drill covered by surface damage. SEM analysis demonstrated that repeated autoclave sterilization cycles had no effect on the zirconia and steel drills.

The purpose of the present investigation was to study the influence of disinfection and sterilization on the implant drill surfaces. The authors hypothesized that zirconia drills may offer a greater resistance to the action of disinfectants commonly used in clinical practice.

The contact with contaminated surfaces produces destructive hydroxyl free radicals that can attack DNA, membrane lipids, and other essential cell components. Glutaraldehyde is a saturated dialdehyde that has gained wide acceptance as a high-level disinfectant and chemical sterilant [14]. Aqueous solutions of glutaraldehyde are "activated" by using alkalinating agents to bring the $\mathrm{pH}$ to values between 7.5 and 8.5 , which makes the solution sporicidal $[15,16]$. Glutaraldehyde (GAA) solutions are used for the sterilization of medical devices, such as endoscopes and fibroscopes. Hydrogen peroxide has good bactericidal, sporicidal, viricidal, and fungicidal properties [17]. However, both glutaraldehyde and hydrogen peroxide are corrosive to steel instruments.

Implant drills are reusable medical devices and implant bed preparation with drills is an invasive procedure involving contact of the drill with blood, bone, and other biological fluids. The major risk of all such procedures is the introduction of drill particles and transfer of pathogens, potentially leading to infection [18]. The main objective of disinfecting or sterilizing drills is to eliminate the transmission of pathogens by means of contaminated medical and surgical devices (e.g., HIV, HCV, Mycobacterium tuberculosis, and encephalopathies) $[19,20]$. Today, the disinfection of medical devices such as implant drills is very important for preventing the emergence of transmissible spongiform, such as the encephalopathies (TSEs), which is a prion protein less susceptible to denaturation by heat and is responsible for disease such as variant Creutzfeldt-Jakob [21]. Therefore, the predicable cleaning of implant drills is believed to be a key procedure for reducing the risks of onward transmission of infectious diseases and pathogens such as human immunodeficiency virus (HIV), hepatitis B and C, gram-negative and gram-positive bacteria, fungi, and preventing the risk of mycobacteria transmission. In addition to microbial inactivation, the removal of organic or inorganic debris is crucial as it may compromise subsequent disinfection or sterilization processes [22]. The cleaning of reusable implant drills is also important in order to ensure drill longevity and efficiency in cutting bone, also making the removal of organic and chemical residues important. The effect of liquid chemical sterilant depends on cleaning to eliminate organic and inorganic material, an optimal $\mathrm{pH}$, concentration, contact time, and temperature are all paramount. During chemical disinfection, it is important that implant drills are not mixed with other drills, or other instruments of different material composition in order to avoid chemical corrosion. In this study, once chemical disinfection was completed, we proceeded to heat sterilization at $134^{\circ} \mathrm{C}\left(273^{\circ} \mathrm{F}\right)$ for $35 \mathrm{~min}$.

It is known that the effect of disinfectants and sterilization can influence the cutting efficiency of drills $[5,23]$. The material that constitutes an osteotomy drill must also have a good resistance to corrosion, which is one of the factors responsible for the loss of cutting efficiency. The drills used for the preparation of implant sites must undergo decontamination and sterilization procedures before being reused on another patient. After every use, reusable medical devices must be rinsed, cleaned, and immediately immersed in an approved medical grade chemical disinfectant with a recognized effectiveness against HIV in accordance with Italian legislation art. 2 Ministerial Decree 28.09.90 [24]. The Ministerial Decree (DMS) imposes a set of rules for the protection of professionals from a broad range of infections in public and private health and care facilities. The objectives of these precautions 
are to prevent the transmission of pathogenic organisms through blood and biological fluids. The cleansing occurs as a result of the chemical actions of a detergent that must be used at recommended concentrations and contact times. It is necessary to frequently renew the solution in order to avoid the accumulation of debris and contamination, which both decrease the detergent efficacy.

Implant surgical procedures expose patients, surgeons, and staff to potential cross-infections if carried out without a series of cleaning and sterilization procedures aimed at preventing the spread of pathogens. Bone drills are classified as critical surgical objects according to the classification proposed by E.H. Spaulding [25] and from the DMS dated 28/9/90 as instruments that come in contact with bleeding tissues and body fluids. For this reason, implantology drills must also be subjected to decontamination and cleaning procedures using chemical substances before proceeding to heat sterilization with saturated steam in an autoclave. All these procedures and protocols can alter the cutting efficiency, as well as deteriorate the depth marks printed on the drills, thereby altering the references that the surgeon has during surgery to check the working depth of the osteotomy. The reduction in cutting efficiency has considerable repercussions for the preparation of the implant site because a loss of sharpness and cutting efficiency of the drill results in a large part of the cutting energy being transformed into heat. The consequences manifest themselves as poor organization of the clot, delayed healing, and poor quality of the tissues that form at the bone-implant interface $[18,26]$. As reported previously in another study [18], implant osteotomy drills can be reused up to 50 times since their loss of sharpness is directly proportional to the number of osteotomies made.

Chemical detergents can cause metal corrosion with alteration of the cutting edge of the drill blades, which is a process that can worsen when the drills are submitted to saturated steam sterilization. In the literature, there are several articles that have studied the degree of wear of osteotomy drills in relation to their reuse $[26,27]$. On the other hand, there is no published work investigating the problem of chemical decontamination or metal release in the bone from surgical drills. In the present work, we chose to separately study the effect on bone drills of the two different chemical agents and the effect of autoclave sterilization in order to understand which of these aspects of bone instrument care is the most critical and potentially damaging to the drills.

We observed that all the disinfectants used were found to be potentially harmful to steel drills, causing corrosion zones that worsened after each decontamination cycle, while the zirconia drills did not show any structural damage, and the depth marks were preserved and remained clearly visible. No damage was observed for the steel and zirconia drills when they were only subjected to autoclave sterilization cycles. The results of the present study provide practical and valuable information that can help conserve the cutting efficiency of the drills by preventing metal release and overheating of the bone, both of which can increase the chances of implant failure [28].

Identifying factors and mechanisms with regards to implant failures should not be limited to the implants, but should also include the host and the drills. Drills are one of the main components of an implant procedure and play an important role in the success of an implant procedure [29,30]. Therefore, it is of primary importance to identify critical factors and develop appropriate therapies and prevention strategies. It is extremely useful to know the histopathology (macroscopic and microscopic aspects of the disease), the pathogenesis (source of the disease), and the physiopathology (mechanism of the disease) of the complications of implant failures, as well as changes in the structure of the bone drills during the processes of decontamination, cleaning, and sterilization.

From the results observed during this study, it is clear that the disinfectants used in clinical practice are potentially harmful to steel drills by contributing to corrosion of their surfaces and the loss of cutting efficiency.

\section{Conclusions}

The present study demonstrates that repeated immersions of steel drills in disinfecting chemical agents result in corrosion on the surface of steel drills. Conversely, these chemicals do not have any effect on zirconia ceramic drills, proving their inertness and structural stability, even in the harshest 
environment. Autoclave sterilization cycles have no effect on any of the drills. Cleansing, sterilization, and maintenance of the drills are crucially important for patients' health and protection, but also for the drills' long-term durability and performance. It can be concluded that zirconia ceramic drills offer a surface that is not affected by disinfecting liquids. The fact that zirconia is immune to corrosion attack eliminates the possibility of the release of microparticles and ions in the peri-implant tissue during osteotomy, thus minimizing the chance of aseptic osteolysis [31].

Author Contributions: Conceptualization, A.S.; data curation, A.S.; formal analysis, S.N. and S.G.; investigation, A.S.; methodology, A.S.; project administration, A.S.; software, F.L. and P.S.; supervision, P.S.; F.I.; validation, A.S., S.N., F.I., and S.G.; visualization, P.S. and F.L.; writing—original draft, A.S.; writing—review and editing, S.N.

Funding: This research received no external funding.

Conflicts of Interest: The authors declare no conflict of interest.

\section{References}

1. Scarano, A.; Piattelli, A.; Quaranta, A.; Lorusso, F. Bone Response to Two Dental Implants with Different Sandblasted/Acid-Etched Implant Surfaces: A Histological and Histomorphometrical Study in Rabbits. BioMed Res. Int. 2017, 2017, 8724951. [CrossRef] [PubMed]

2. Eriksson, A.; Albrektsson, T. Temperature threshold levels for heat-induced bone tissue injury: A vital-microscopic study in the rabbit. J. Prosthet. Dent. 1983, 50, 101-107. [CrossRef]

3. Scarano, A.; Carinci, F.; Lorusso, F.; Festa, F.; Bevilacqua, L.; Santos de Oliveira, P.; Maglione, M. Ultrasonic vs Drill Implant Site Preparation: Post-Operative Pain Measurement through VAS, Swelling and Crestal Bone Remodeling: A Randomized Clinical Study. Materials 2018, 11, 2516. [CrossRef] [PubMed]

4. Eriksson, R.; Adell, R. Temperatures during drilling for the placement of implants using the osseointegration technique. J. Oral Maxillofac. Surg. 1986, 44, 4-7. [CrossRef]

5. Scarano, A.; Di Carlo, F.; Piattelli, A. Effect of sterilization and cleansing on implantology drills: Zirconia vs steel. Ital. Oral Surg. 2008, 3, 61-72.

6. Hochscheidt, C.J.; Shimizu, R.H.; Andrighetto, A.R.; Pierezan, R.; Thomé, G.; Salatti, R. Comparative Analysis of Cutting Efficiency and Surface Maintenance between Different Types of Implant Drills: An In Vitro Study. Implant Dent. 2017, 26, 723-729. [CrossRef] [PubMed]

7. Hein, C.; Inceoglu, S.; Juma, D.; Zuckerman, L. Heat Generation during Bone Drilling: A Comparison between Industrial and Orthopaedic Drill Bits. J. Orthop. Trauma 2017, 31, e55-e59. [CrossRef] [PubMed]

8. Louropoulou, A.; Slot, D.E.; Van der Weijden, F.A. Titanium surface alterations following the use of different mechanical instruments: A systematic review. Clin. Oral Implant. Res. 2012, 23, 643-658. [CrossRef]

9. Noumbissi, S.; Scarano, A.; Gupta, S. A Literature Review Study on Atomic Ions Dissolution of Titanium and Its Alloys in Implant Dentistry. Materials 2019, 12, 368. [CrossRef]

10. Dubruille, J.H.; Viguier, E.; Le Naour, G.; Dubruille, M.T.; Auriol, M.; Le Charpentier, Y. Evaluation of combinations of titanium, zirconia, and alumina implants with 2 bone fillers in the dog. Int. J. Oral Maxillofac. Implant. 1999, 14, 271-277.

11. Scarano, A.; Di Carlo, F.; Quaranta, M.; Piattelli, A. Bone Response to Zirconia Ceramic Implants: An Experimental Study in Rabbits. J. Oral Implant. 2003, 29, 8-12. [CrossRef]

12. Jackson, M.C. Restoration of posterior implants using a new ceramic material. J. Dent. Technol. 1999, 16, 19-22. [PubMed]

13. Spinelli, M.; Maccauro, G.; Graci, C.; Cittadini, A.; Magnani, G.; Sangiorgi, S.; Del Bravo, V.; Manicone, P.; Raffaelli, L.; Muratori, F.; et al. Zirconia Toughened Alumina (ZTA) Powders: Ultrastructural and Histological Analysis. Int. J. Immunopathol. Pharmacol. 2011, 24, 153-156. [CrossRef] [PubMed]

14. Lin, W.; Niu, B.; Yi, J.; Deng, Z.; Song, J.; Chen, Q. Toxicity and Metal Corrosion of Glutaraldehyde-Didecyldimethylammonium Bromide as a Disinfectant Agent. BioMed Res. Int. 2018, 2018, 9814209. [CrossRef] [PubMed]

15. Urayama, S.; Kozarek, R.A.; Sumida, S.; Raltz, S.; Merriam, L.; Pethigal, P. Mycobacteria and glutaraldehyde: Is high-level disinfection of endoscopes possible? Gastrointest. Endosc. 1996, 43, 451-456. [CrossRef]

16. Chenjiao, W.; HongYan, Z.; Qing, G.; Xiaoqi, Z.; Liying, G.; Ying, F. In-Use Evaluation of Peracetic Acid for High-Level Disinfection of Endoscopes. Gastroenterol. Nurs. 2016, 39, 116-120. [PubMed] 
17. Omidbakhsh, N.; Sattar, S.A. Broad-spectrum microbicidal activity, toxicologic assessment, and materials compatibility of a new generation of accelerated hydrogen peroxide-based environmental surface disinfectant. Am. J. Infect. Control 2006, 34, 251-257. [CrossRef]

18. Scarano, A.; Carinci, F.; Quaranta, A.; Di Iorio, D.; Assenza, B.; Piattelli, A. Effects of Bur Wear during Implant Site Preparation: An in Vitro Study. Int. J. Immunopathol. Pharmacol. 2007, 20, 23-26. [CrossRef]

19. Bagg, J.; Smith, A.J.; Hurrell, D.; McHugh, S.; Irvine, G. Pre-sterilisation cleaning of re-usable instruments in general dental practice. Br. Dent. J. 2007, 202, E22. [CrossRef]

20. Laheij, A.M.G.A.; Kistler, J.O.; Belibasakis, G.N.; Välimaa, H.; de Soet, J.J.; European Oral Microbiology Workshop (EOMW) 2011. Healthcare-associated viral and bacterial infections in dentistry. J. Oral Microbiol. 2012, 4. [CrossRef]

21. Bourgeois, D.; Dussart, C.; Saliasi, I.; Laforest, L.; Tramini, P.; Carrouel, F. Observance of Sterilization Protocol Guideline Procedures of Critical Instruments for Preventing Iatrogenic Transmission of Creutzfeldt-Jakob Disease in Dental Practice in France, 2017. Int. J. Environ. Res. Public Health 2018, 15, 853. [CrossRef] [PubMed]

22. Douet, J.Y.; Lacroux, C.; Aron, N.; Head, M.W.; Lugan, S.; Tillier, C.; Huor, A.; Cassard, H.; Arnold, M.; Beringue, V.; et al. Distribution and Quantitative Estimates of Variant Creutzfeldt-Jakob Disease Prions in Tissues of Clinical and Asymptomatic Patients. Emerg. Infect. Dis. 2017, 23, 946-956. [CrossRef] [PubMed]

23. Scarano, A.; Assenza, B.; Di Iorio, D.; Quaranta, A. Effect of sterilization and cleansing on implantology drills. Ital. Oral Surg. 2008, 2, 4-13.

24. Ministero della Sanità. Norme di Protezione dal Contagio Professionale da HIV Nelle Strutture Sanitarie e Assistenziali Pubbliche e Private; Ministero della Sanità: Rome, Italy, 1990.

25. Spaulding, E.H. Chemical disinfection and antisepsis in the hospital. J. Hosp. Res. 1972, 9, 5-31.

26. Tehemar, S.H. Factors affecting heat generation during implant site preparation: A review of biologic observations and future considerations. Int. J. Oral Maxillofac. Implant. 1999, 14, 127-136.

27. Rutala, W.A.; Weber, D.J. Disinfection, sterilization, and antisepsis: An overview. Am. J. Infect. Control 2016, 44, e1-e6. [CrossRef] [PubMed]

28. Scarano, A.; Piattelli, A.; Assenza, B.; Carinci, F.; Di Donato, L.; Romani, G.L.; Merla, A. Infrared thermographic evaluation of temperature modifications induced during implant site preparation with cylindrical versus conical drills. Clin. Implant Dent. Relat. Res. 2011, 13, 319-323. [CrossRef] [PubMed]

29. Sridhar, S.; Wilson, T.G.; Valderrama, P.; Watkins-Curry, P.; Chan, J.Y.; Rodrigues, D.C. In Vitro Evaluation of Titanium Exfoliation during Simulated Surgical Insertion of Dental Implants. J. Oral Implant. 2016, 42, 34-40. [CrossRef]

30. Scarano, A.; Piattelli, A.; Polimeni, A.; Di Iorio, D.; Carinci, F. Bacterial Adhesion on Commercially Pure Titanium and Anatase-Coated Titanium Healing Screws: An In Vivo Human Study. J. Periodontol. 2010, 81, 1466-1471. [CrossRef]

31. Scarano, A.; Cholakis, A.; Piattelli, A. Histologic Evaluation of Sinus Grafting Materials after Peri-implantitis-Induced Failure: A Case Series. Int. J. Oral Maxillofac. Implant. 2017, 32, e36-e75. [CrossRef]

(C) 2019 by the authors. Licensee MDPI, Basel, Switzerland. This article is an open access article distributed under the terms and conditions of the Creative Commons Attribution (CC BY) license (http://creativecommons.org/licenses/by/4.0/). 